\title{
O USO DE ANÁLISE CONTEXTUAL DE TAREFAS PARA A GESTÃO DA PROPRIEDADE INTELECTUAL
}

\author{
EL USO DE ANÁLISIS CONTEXTUAL DE TAREAS PARA LA \\ GESTIÓN DE LA PROPIEDAD INTELECTUAL
}

\author{
Eliandro dos Santos Costa - eliandrocosta@gmail.com \\ Mestrando do Curso de Engenharia da Produção da \\ Universidade Federal de Santa Maria, UFSM - Bolsista do CNPq \\ Andre Zanki Cordenonsi - andrezc@inf.ufsm.br \\ Doutor em Informática na Educação pela Universidade Federal do \\ Rio Grande do Sul. Professor da Universidade Federal de Santa Maria, UFSM
}

Julio Cezar Mairesse Siluk - jsiluk@gmail.com Doutor em Engenharia de Produção pela Universidade Federal de Santa Catarina. Professor da Universidade Federal de Santa Maria, UFSM

Felipe Martins Müller - felipe@inf.ufsm.br Doutor em Engenharia Elétrica pela Universidade Estadual de Campinas. Professor Titular da Universidade Federal de Santa Maria, UFSM.

\begin{abstract}
Resumo
Apresenta o processo de desenvolvimento de um modelo para sistema de gestão de propriedade intelectual por meio do uso de metodologia de análise contextual de tarefas, a qual visa desenvolver a modelagem sob a visão do usuário. Apresenta um estudo de caso, onde é empregada a abordagem sugestionada para o levantamento de requisitos. Tem como objetivo desenvolver um modelo que apresente melhorias na gestão de processos de proteção de propriedade intelectual, e que forneça dados que explicitem a importância do uso de ferramentas gerenciais como forma de melhoria no desempenho da proteção da produção intelectual da organização. Os resultados obtidos por meio do desenvolvimento de fluxos e com a estruturação das atividades foram positivos, melhorando a eficiência da recuperação de dados e conseqüentemente o aumento da capacidade de inovar da organização.
\end{abstract}

Palavras-chave

Inovação. Análise de Requisitos. Análise de Tarefas. Propriedade Intelectual. Gestão da Inovação. 


\section{INTRODUÇÃO}

No contexto atual, pode-se descrever um quadro de mudança com grandes tendências ao envolvimento do capital intelectual como fator chave de sucesso para o desenvolvimento e aprimoramento das nações. Nesse ponto, considera-se a valoração do talento humano e o seu grande potencial de visão de ações estratégicas e práticas a serem idealizadas para a melhoria do ambiente de trabalho em qualquer natureza.

Esse artigo dá preferência em trabalhar uma pesquisa para desenvolvimento de um modelo de sistema sob a ótica do próprio usuário, o qual está envolvido na atividade-fim do organismo. Assim, objetiva-se obter os requisitos necessários, através da elaboração de fluxos de trabalho, os quais possam contribuir de inúmeras formas, desde a identificação da situação atual até as necessidades de melhorias na tramitação de processos de trabalho, que por sua vez contêm os documentos e suas exigências em cada fase para 0 cumprimento da atividade de gerência do processo.

Nesse panorama, vê-se um ambiente de formação de potencial intelectual, como altamente propício para a experimentação de uma proposta desse nível, onde se pode trabalhar com toda a visão sistêmica da organização e multidisciplinar, gerando propostas de forma dinâmica e já adequadas com as constantes mudanças e competitividade do mercado e das tecnologias.

Seguindo-se, foi escolhido como estudo de caso o Núcleo de Inovação e Transferência de Tecnologia (NIT) ${ }^{1}$ da Universidade Federal de Santa Maria $(\mathrm{UFSM})^{2}$, para fazer as experiências de observação e levantamento de informações, sabendo-se sob o seu papel, devidamente descrito no capítulo a seguir, de estimular o exercício da criatividade dos pesquisadores, dispondo de instrumentos de práticas técnico-intelectual e capacitações em propriedade intelectual, as quais contribuam para o desenvolvimento de um perfil com maior potencial inovador e tecnológico para a UFSM.

Esse órgão é referência na Instituição, como disseminador da cultura da propriedade intelectual e da inovação. É considerado como fator estratégico e primordial para o melhor aproveitamento da produção científica, funcionando como um ativo cognitivo derivado da aprendizagem tecnológica, o qual se trata de um processo que envolve vários mecanismos que captam diversos tipos de conhecimento a partir de fontes externas e internas à organização (FIGUEIREDO, 2009).

Esse mesmo autor descreve a aprendizagem como fonte de insumo para a construção e acumulação de capacidade tecnológica e realização de atividades tecnologicamente inovadoras, principalmente se considerar o ambiente de uma instituição de ensino superior, "berçário" de criatividade e empreendedorismo (FIGUEIREDO, 2009).

A potencialidade visível nos bancos universitários forma uma estrutura consistente para a geração de conhecimento tácito de produção científica,

Disponível no endereço eletrônico: <www.ufsm.br/nit>, acesso em 15 out 10.

Disponível no endereço eletrônico: <www.ufsm.br>, acesso em 15 out 10. 
podendo resultar na criação de invenções e, a partir disso, quando transferidos para o mercado, podendo gerar as ditas inovações. Esse ambiente torna-se altamente propício para 0 avanço tecnológico, principalmente por ser fundamentado em fatores interdisciplinares entre diversas áreas promovendo pesquisas que podem afetar diretamente o mercado e a sociedade.

Ressaltando a importância do uso da informação para o mercado atual, Tonsig (2003) distingue as organizações em dois grupos: o primeiro grupo são as que buscam atingir lucro e o segundo grupo são aquelas que são ditas sem fins lucrativos. Entretanto, ambas essas organizações necessitam e dependem de informação para realizar suas atividades, ainda que seus fins sejam diferenciados.

A informação é elemento primordial para a tomada de decisão, servindo de guia para as ações, desde esclarecer como cada tarefa foi tratada e assim, evidenciando o melhor caminho a ser seguido para a solução de qualquer problema (TONSIG, 2003).

Os termos "tecnologia", "inovação", "capacidade tecnológica" e "aprendizagem tecnológica" são expressões muito utilizadas como base fundamental para tomada de decisão e planejamento estratégico das organizações, em se tratando do nível de desenvolvimento exigido dos profissionais para o mercado, os quais podem ser potencializados desde a academia, com uma formação direcionada para a prática inovadora, envolvendo uma atuação multidisciplinar e proativa, favorecendo as empresas no fator competitividade.

Vital, Floriani, Varvakis (2010) destacam como requisito da gestão da informação, a importância do estabelecimento de processos, etapas ou fluxos sistematizados e estruturados, associado às pessoas responsáveis por sua condução, para que se obtenham os resultados almejados. Essa visão trata do fluxo como suporte para a tomada de decisão, formando um bom subsídio para estruturar fluxogramas das atividades do gerenciamento da propriedade intelectual propositada nesse artigo.

Conforme Canongia e colaboradores (2004), as empresas estão crescentemente mais perceptíveis da importância da Gestão da Inovação para a competitividade, entretanto carecem de instrumentos mais adequados que possam dispor de funcionalidades e questões geradas da própria essência dos processos de invenção como a incerteza dos resultados e a capacidade da análise de rotas alternativas para sua produção.

A inovação deve vir como solução de um ambiente que produz ciência de ponta e influenciar direta e indiretamente o setor produtivo através de pesquisas em C\&T, focalizando resultados palpáveis e práticos com respaldo confiável e mercado abrangente, em crescimento ou favorável ao empreendimento. A inovação acontece somente no mercado, pois a universidade produz subsídios tecnológicos na forma de invenções dos mais diversos fins e gerada nos mais distintos meios aceitáveis.

Tratando dos fatores que vinculam essa pesquisa à administração e à gestão, Calderon e colaboradoras (2004) referem-se ao ato de gerenciar muito além do simples ato de registro da informação em um suporte (papel, fita magnética, CD-r, disco rígido, etc.), pois é necessário haver planejamento para se obter os resultados esperados com o uso da informação, que nessa situação 
especifica diretamente a informação de cunho tecnológico gerada da produção científica das instituições. Essa informação é armazenada, nos dias atuais, nas bases de patentes nacionais e internacionais, e pode ser identificada disponível em ambiente web, acessível para todo o tipo de usuário, bem como pode ser encontrada em período de sigilo.

A gestão pode ser vista como um conjunto de processos que envolvem atividades de planejamento, organização, direção, distribuição e controle de recursos de qualquer natureza, esperando gerar a melhor racionalização e a efetividade de determinado sistema, produto ou serviço (OLIVEIRA et al., 2010).

Considerando a contribuição gerada dessa pesquisa para o processo de tomada de decisão e o bom desempenho do fluxo de informação de propriedade intelectual, apresenta-se a proposta de um processo de desenvolvimento de uma modelagem de sistema para a gestão da propriedade intelectual (SGPI), o qual possa vir a contribuir para a melhoria da qualidade e do desempenho dos processos de encaminhamento de proteção de propriedade intelectual, facilitando a geração de um maior número de invenções depositadas por período, de forma mais estruturada e adequada cumprindo as exigências dos órgãos reguladores e ambientalizadas nas necessidades do mercado.

Esse sistema será formado através da união de funcionalidades de módulos já existentes junto ao um sistema maior e já adotado na instituição, denominado Sistema de Informações para o Ensino $^{3}$ (S.I.E.) (Figura 1).

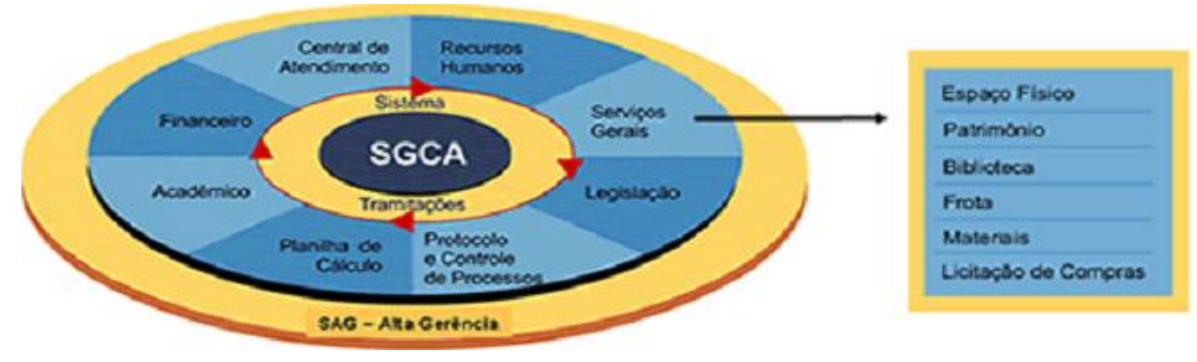

Figura 1 "Pizza" dos módulos do SIE Fonte: UFU (http://www.sie.ufu.br/)

O desenvolvimento do SIE foi baseado nas especificações fornecidas pela Unidade de Coordenação de Programas - UCP do Ministério da Fazenda, e da Comissão de Informática da FATEC/UFSM/MEC, visando à adequação dos requisitos às Instituições de Ensino do Brasil.

A metodologia dessa pesquisa, como será vista em capítulo específico a seguir, é baseada no uso da técnica de Análise Contextual de Tarefas, a qual propõe que o investigador experiencie o trabalho do usuário na expectativa de compreender a sua cultura laboral ou o exercício da sua atividade diária

\footnotetext{
${ }^{3}$ O SIE é um projeto apoiado pela Secretaria de Ensino Superior (SESu) do MEC, que objetivou desenvolver um Sistema que servisse para a Gestão das IFES Brasileiras. O projeto foi desenvolvido pelo CPD da UFSM. Atua na gestão integrada, envolvendo todas as atividades de uma IES, as quais são desenvolvidas e acompanhadas através dele.
} 
(HOELZEL, 2004). Essa filosofia de pensar no usuário consiste em envolvê-los no processo de desenvolvimento do produto, mesmo que esse venha a agregar um novo valor.

No capítulo de resultados, pode-se visualizar os fluxogramas propositados, os quais irão servir de recurso para o desenvolvimento do SGPI. Na sequência, tem-se as conclusões, as quais expõem as contribuições geradas dessa pesquisa e a importância desse trabalho receber uma continuidade e/ou aplicação junto uma interação multidisciplinar para incrementar melhorias ao ambiente produtivo acadêmico e sua interação com o mercado.

\section{O NÚCLEO DE INOVAÇÃO E TRANSFERÊNCIA DE TECNOLOGIA - NIT}

O NIT da UFSM foi criado através da Resolução nº. 005/2005, de 19 de abril de 2005, inicialmente vinculado a Pró-reitoria de Pós-graduação e Pesquisa (PRPGP) e em seguida ligado ao Gabinete do Reitor, através da Resolução nº. 019/2007, o qual definiu as atribuições e novas regulamentações para a gestão da propriedade intelectual na UFSM. A estrutura do NIT é composta por um conselho gestor, um diretor, uma Secretaria de Apoio Administrativo e pelas Assessorias de Propriedade Intelectual, Informação Tecnológica e Transferência de Tecnologia.

O NIT é um agente mediador entre o mercado, a universidade e o governo, exercendo importante papel para a gestão da propriedade intelectual, da inovação tecnológica e da transferência da tecnologia, favorecendo o desenvolvimento do mercado, como contributo da academia, a qual fornece o retorno à sociedade decorrente de suas pesquisas e atividades de produção científica que, em sua maioria, visam promover desenvolvimento para a sociedade.

Segundo Etzkowitz (2009), a universidade é o princípio gerador das sociedades fundadas no conhecimento, assim como o governo e a indústria são as instituições primárias na sociedade industrial. E o diferencial da universidade em relação aos demais ambientes de produção do conhecimento são os estudantes, incluindo a constante renovação do quadro discente com ingresso periódico de novos alunos, renovando as idéias e favorecendo as unidades de P\&D.

A universidade acaba assumindo o papel da indústria quando passa a incentivar a formação de novas empresas a partir da pesquisa, estabelecendo a "capitalização do conhecimento". A hélice tríplice se concentra na universidade, como fonte de empreendedorismo e tecnologias, assim como de investigações críticas. E esse empreendedorismo na universidade acontece através da transferência da tecnologia, da incubação de novas empresas e da condução de esforços de renovação regionais (ETZKOWITZ, 2009).

O modelo de hélice tríplice (Figura 2), proposto, retrata que a geração de riqueza e o desenvolvimento local podem ser realizados através da inovação e gestão do conhecimento, envolvendo Universidade, Empresa e Governo (ETZKOWITZ, 2009). Ainda segundo este modelo, as relações entre Universidade, Governo e Empresa geram uma hélice ascendente de desenvolvimento regional que advém do fato de que o fluxo de conhecimento 
entre universidades e empresas faz com que estas adquiram maior competitividade, por meio de produtos mais densos em conhecimento. No contexto da hélice tríplice, a universidade passa a ter um novo papel no Sistema Regional de Inovação tornando-se um ator de grande importância.

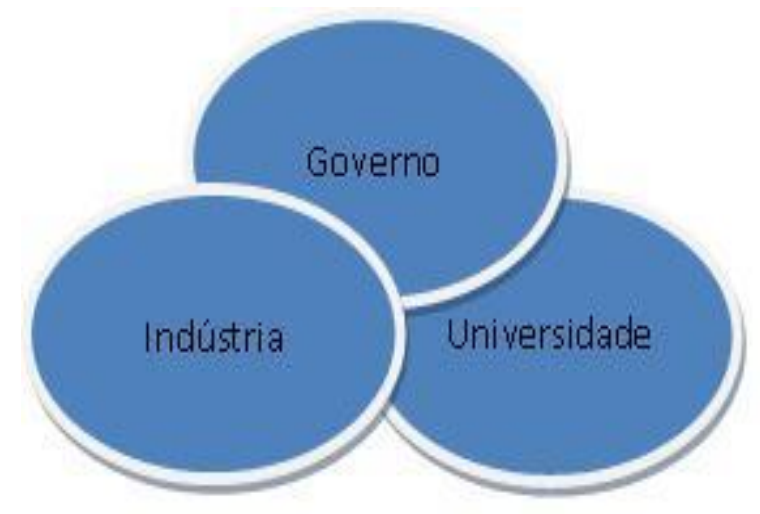

Figura 2 Modelo de Hélice Tríplice

Fonte: Etzkowitz (2009)

O NIT se enquadra nesse modelo de Hélice Tríplice, considerando que é o órgão responsável da UFSM, por promover a adequada proteção das invenções e a sua transferência para o setor empresarial, visando a integrar a universidade com a comunidade e contribuir para o desenvolvimento cultural, tecnológico e social da região e do país.

No panorama nacional e internacional, tem-se o Instituto Nacional de Propriedade Industrial ${ }^{4}$ (INPI) como órgão regulador da Propriedade Intelectual. Diretamente envolvido dentro do desenvolvimento das atividades-fim do NIT.

O NIT vem desenvolvendo inúmeras atividades para a recuperação das informações contidas nos documentos de patentes, os quais podem e devem ser utilizadas como base para estimular o crescimento econômico dos países em desenvolvimento e de menor desenvolvimento relativo, e no aumento da competitividade entre os países desenvolvidos.

\section{METODOLOGIA}

O processo de desenvolvimento de ferramentas gerenciais pode apresentar um maior nível de satisfação no atendimento dos requisitos e funcionalidades, quando pensado sob a realidade do ambiente a ser implementado. Essa experimentação é precedida de uma longa trajetória de análise e aplicação de modelos teóricos adaptados para a realidade da organização, considerando que não há fórmula padrão para todas as situações encontradas, mesmo em se tratando que essas possuam as mesmas atividadesfim e/ou meio.

$4 \quad$ Fonte: <www.inpi.gov.br>; Acesso em 28 Nov 09 
O processo científico para o levantamento de requisitos, pode qualificar as hipóteses e convertê-las em prescrições passíveis de serem implementadas na realidade empresarial e organizacional (SCHERER; CARLOMAGNO, 2009). Pode-se obter fluxos mais claros e comprovados pelo próprio usuário, o qual será ator de teste e uso do modelo desenvolvido.

Segundo Scherer e Carlomagno (2009), o primeiro passo é definir o fenômeno que se quer compreender e obter conhecimento sobre as atividades exercidas. Em seguida, deve-se categorizar o fenômeno em módulos e/ou funções que transpareçam o melhor entendimento de como funciona a organização. Tendo isso, pode-se passar para o passo da teorização, onde se encaminha para a tentativa de formatação de uma hipótese sobre o que causa o fenômeno e suas justificativas.

Assim, é relevante descrever as tarefas de cada atividade-fim do NIT, mais especificamente nas patentes, onde se trabalha desde a sua interação com 0 Pesquisador, passando pelo seu encaminhamento através dos formuláriospadrão, indo até a transferência dessa tecnologia para o mercado, com o devido recolhimento de royalties. Essas três fases formam um modelo de formação de teorias (Figura 3).

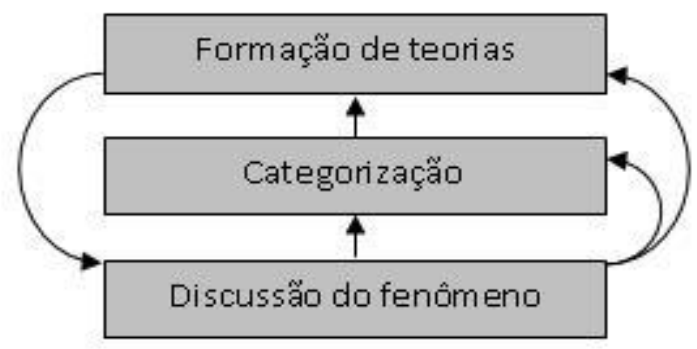

Figura 3 Modelo de formação de teorias

Fonte: Cristiensen e Raynor (2003) apud Scherer e Carlomagno (2009), p. 73

Preece, Rogers e Sharp (2005) ressaltam sobre um usuário que possui a tendência de apegar-se a algo que sabe que funciona bem (viscosidade), que já esta apresentando resultados, mesmo esses não sendo tão positivos em relação às necessidades do ambiente. Quando se observa uma nova solução, utiliza-se o fator criatividade como qualidade essencial na criação de novos requisitos, mesmo sabendo que muito pouco nesse ambiente é completamente novo, podendo ser melhoria ou adaptação do que já existe.

Para tanto, essa pesquisa adota a técnica de análise contextual de tarefas para investigação de situações existentes, analisando o que as pessoas estão fazendo e o que estão tentando criar ou realizar e ainda porque e como estão trabalhando com isso. O que se obtém dessa análise estabelece uma base de práticas existentes nas quais se podem construir novos requisitos ou projetar novas tarefas.

Preece, Rogers e Sharp (2005) tratam ainda que, a análise de tarefas é uma expressão mais abrangente que envolve técnicas para o estudo de processos cognitivos e ações físicas em um alto nível de abstração. Existem 
várias técnicas de análise de tarefas, como a $\mathrm{AHT}^{5}$ (Análise Hierárquica de Tarefas) e a GOMS ${ }^{6}$ (do inglês goals, operations, methods e selection rules).

Entretanto, nessa pesquisa adotou-se a análise contextual de tarefas, considerando como principal vantagem unir os aspectos internos do funcionamento da aplicação com a interface que o usuário espera para o software que está sendo desenvolvido.

A análise contextual de tarefas é uma técnica de investigação da Interação Humano-Computador (IHC). Conceitualmente, essa técnica estuda situações existentes, realizando uma análise desde o início do ciclo de desenvolvimento, quando se faz a identificação dos requisitos, permitindo saber quem vai usar a interface e o quê irá fazer nela. Ela é considerada uma ferramenta colaborativa e acessória para a identificação de requisitos de um sistema. Usualmente, esta técnica descreve os passos que um usuário faz para completar uma tarefa e, em alguns casos, como ele realiza essas tarefas.

Pode-se expôr um comparativo entre a análise de sistema tradicional e a análise contextual de tarefas (Quadro 1), demonstrando as diferenças entre as duas abordagens, evidenciando as vantagens no uso da técnica, para a obtenção de melhores resultados:

\begin{tabular}{|l|l|l|}
\hline Metas & Análise de Sistemas Tradicional & Análise Contextual de Tarefa \\
\hline Saídas & $\begin{array}{l}\text { Entradas para o design de processo de } \\
\text { software e estruturas de dados }\end{array}$ & $\begin{array}{l}\text { Entradas para o design de interface } \\
\text { do usuário }\end{array}$ \\
\hline Iados de funções e modelos de & $\begin{array}{l}\text { Análises dos ambientes de } \\
\text { trabalho, análise da tarefa, } \\
\text { cenários da tarefa, modelo de } \\
\text { organização da tarefa corrente do } \\
\text { usuário }\end{array}$ \\
\hline Foco & Implementação da arquitetura & $\begin{array}{l}\text { Reengenharia da organização da } \\
\text { tarefa e modelos de sequências } \\
\text { da tarefa, modelo conceitual de } \\
\text { design, design padronizados de } \\
\text { telas e design detalhado da IU }\end{array}$ \\
\hline $\begin{array}{l}\text { Objetos de } \\
\text { análise }\end{array}$ & $\begin{array}{l}\text { Limitações técnicas de processamento de } \\
\text { informação, características de dados e } \\
\text { considerações sobre a implementação } \\
\text { de arquiteturas }\end{array}$ & $\begin{array}{l}\text { Limitações do processamento } \\
\text { humano das informações, trabalho } \\
\text { corrente e modelo de trabalho } \\
\text { corrente do usuário }\end{array}$ \\
\hline
\end{tabular}

Quadro 1 Análise de Sistemas Tradicional vs. Análise Contextual da Tarefa Fonte: Mayhew (1999) apud Hoelzel (2004, p. 42)

\footnotetext{
${ }^{5} \mathrm{AHT}$ - Técnica que identifica as necessidades do treinamento, compreendendo dividir uma tarefa em várias sub-tarefas, especificando como cada tarefa pode ser realizada em uma situação real. ${ }^{6}$ GOMS - Um acrônimo para metas (goals), operadores (operators), métodos (methods) e regras de seleção (selection rules), os quais descrevem como um usuário realiza uma tarefa baseada no computador.
} 
Nessa síntese, a técnica de análise contextual de tarefas apresenta as condições essenciais para a tomada de conhecimento sobre a realidade da organização pesquisada, apresentando uma proposta mais adequada com os requisitos essenciais para o desempenho das atividades de cada usuário, o qual é fonte básica para a obtenção das informações e dados para o desenvolvimento de uma pesquisa desse gênero.

Essa técnica possui seu respaldo na sua simplicidade e fácil compreensão, originado da sua origem na atividade pura do usuário, o qual é vivenciado pelo desenvolvedor.

\section{RESULTADOS}

Nessa seção, será apresentado um levantamento de informações demonstrado através de fluxogramas correspondentes ao funcionamento atual das tarefas do NIT, mais especificamente às atividades voltadas ao atendimento da proteção de propriedade intelectual de pedidos de patentes na Instituição. $O$ mapeamento das atividades desse órgão vem contribuir de forma a esclarecer e estruturar as rotinas de trabalho para que assim, possa se traçar diretrizes junto ao planejamento adequadas às exigências atuais da Instituição e envolvidas na realidade da equipe de trabalho.

Os atores do NIT (descritos nos fluxos) cumprem um elenco de atividades diárias, dentre elas têm-se: atendimento ao público, encaminhamento da documentação do pedido de propriedade intelectual, lançar dados do pedido nos sistemas que auxiliam o Núcleo, dentre outras atividades não consideradas nessa fase da pesquisa, por não serem relevantes para o foco adotado.

Os pesquisadores da Instituição são atores que atuam diretamente no desenvolvimento de tecnologias, as quais irão vir a gerar as invenções passíveis ou não de proteção de propriedade intelectual (produtos, processos, metodologias, softwares, entre outros), conforme o estado da técnica de cada produção desenvolvida ou aprimorada.

Da mesma forma, têm-se o INPI como agente regulador e repositor de informações, responsável pela capacitação em propriedade intelectual e inovação à comunidade, como meio de armazenamento dos conhecimentos protegidos.

Para o desenvolvimento do fluxograma do funcionamento do pedido de proteção de patente utilizou-se o software conhecido por Bizagi ${ }^{7}$. Essa ferramenta ofereceu todas as funcionalidades essenciais para a descrição das tarefas e etapas, focado no conhecimento do usuário do NIT, que por sua vez cumpriu o papel de fonte de tomada do conhecimento sob o contexto do fluxo da informação para a pesquisa.

Outro software utilizado foi o Microsoft Office Access, como banco de dados para a recuperação e tramitação das informações relativas aos processos de proteção de propriedade intelectual no NIT, também como forma de fornecer subsídios e requisitos para o SGPI, definindo os metadados a serem utilizados para a modelagem.

\footnotetext{
${ }^{7}$ O Bizagi é uma ferramenta de software livre de BPMN, que dispõe das funções essenciais para o desenvolvimento de fluxogramas, atuando como ferramenta gerencial para a modelagem de sistemas de gestão dos mais diversos fins. Disponível em: <http://www.bizagi.com>, Acesso em 06 dez 2009.
} 
A decisão de escolher esse software foi por se tratar da facilidade de acesso, sendo que já se encontra o pacote Microsoft Office XP instalado nos computadores do Núcleo, porém ressaltando que esse meio será provisório para ser usado somente até implementar-se o uso do SIE para a gestão dos processos de propriedade intelectual, o qual essa pesquisa vem a contribuir, utilizando-se das funções e recursos disponíveis nos demais módulos já em implementados junto as atividades da Universidade.

Da mesma forma, ressalta-se que a utilização de softwares com padrões fechados torna-se um grande problema para a preservação da informação digital, considerando o grande risco de incompatibilidade e dependência ao fabricante, "amarrando" o detentor do acervo, impedindo de promover melhorias em suas funcionalidades, conforme as necessidades forem surgindo com a expansão da produção informacional ou avanço dos recursos tecnológicos (SANTOS, INNARELLI, SOUZA, 2009).

O SIE é o sistema adotado oficialmente pela instituição, ressaltando-se nisso a importância de sua inserção para uso no NIT, incluindo a capacidade de poder ser melhorado para esse ambiente, tratando de melhor segurança e respaldo legal para a proteção dos seus processos, bem como a uniformização das suas tarefas.

Apresentam-se assim, os fluxogramas e suas respectivas descrições:

\section{Etapa 1 Pesquisador gerando invenção}

Pesquisador (es) ou grupo de pesquisa deve $(\mathrm{m})$ proceder a busca de documentos de patente depositados (busca prévia ou de anterioridade), conforme descrito na Figura 4, como meio de qualificar e embasar os estudos científicos, evitando desperdícios e perdas de investimentos, tempo e dedicação sob algo que pode já ter sido produzido. Entretanto, mesmo se constatando que já encontra no estado da técnica, pode ser encaminhado para licenciamento sem proteção como forma de aproveitamento dos recursos despendidos no desenvolvimento e como meio de interação com o mercado, encurtando fronteiras.

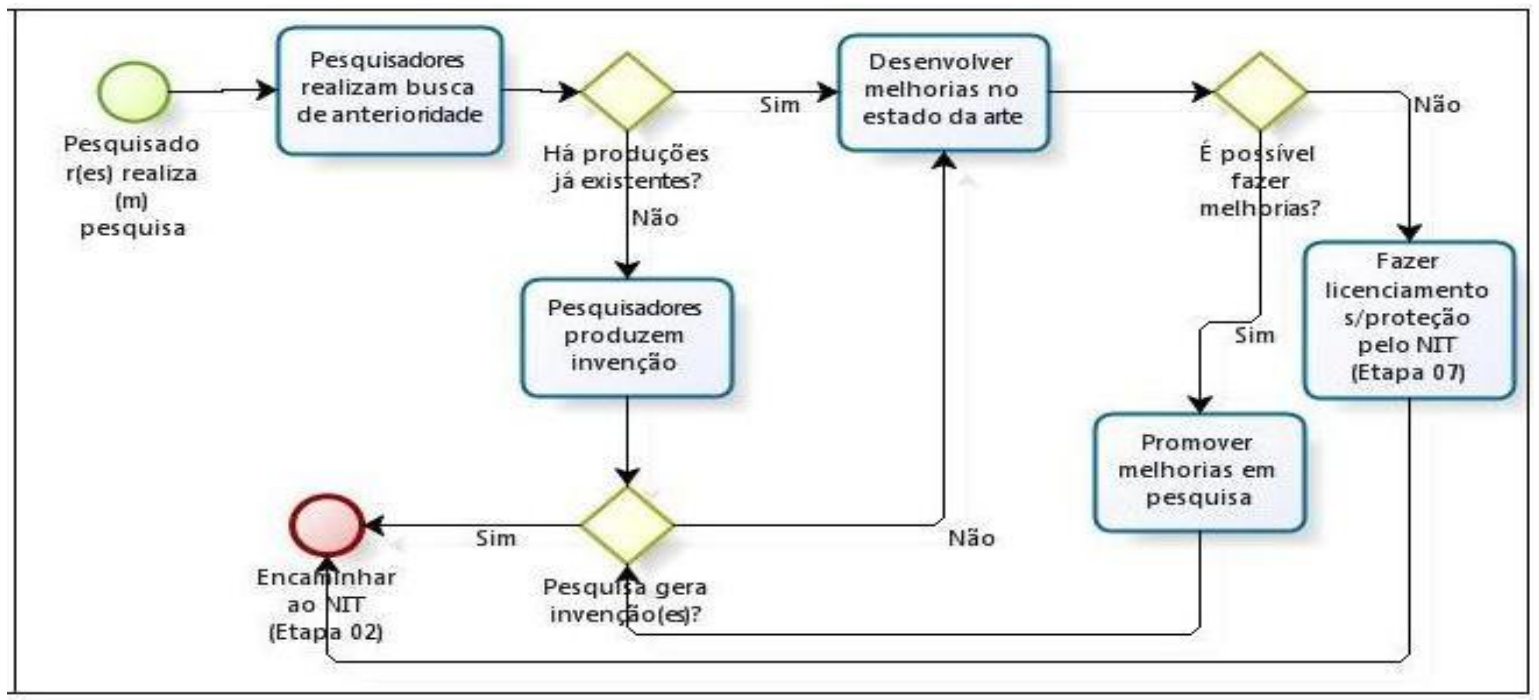

Figura 4 Etapa Pesquisador gerando invenção

Fonte: próprio autor 


\section{Etapa 2 Pesquisador busca o NIT}

Nessa fase o(s) pesquisador(es) procura $(m)$ o NIT, no intuito de encaminhar proteção do conhecimento desenvolvido em sua pesquisa, preenchendo formulários de cadastro da invenção e dos inventores, lançando os dados no sistema (Figura 5).

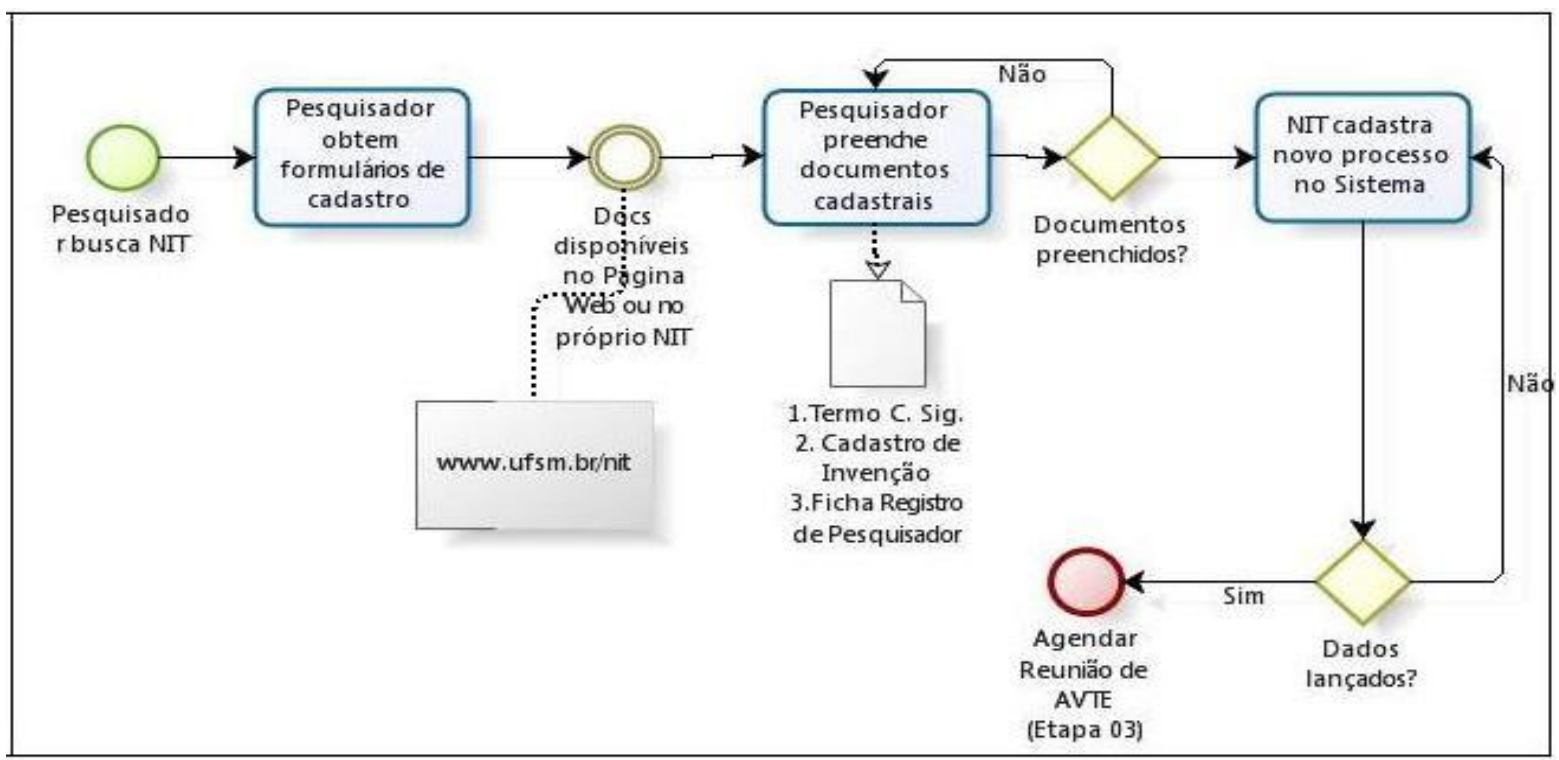

Figura 5 Etapa 2 Pesquisador busca o NIT para encaminhar processo de proteção

Fonte: próprio autor

\section{Etapa 3 Agendamento de Reunião de Avaliação de Pedido}

Estabelece-se contato e faz-se convocação para os profissionais e pesquisadores da área do pedido, para tratar acerca da análise do pedido juntamente com o NIT e os inventores (Figura 6).

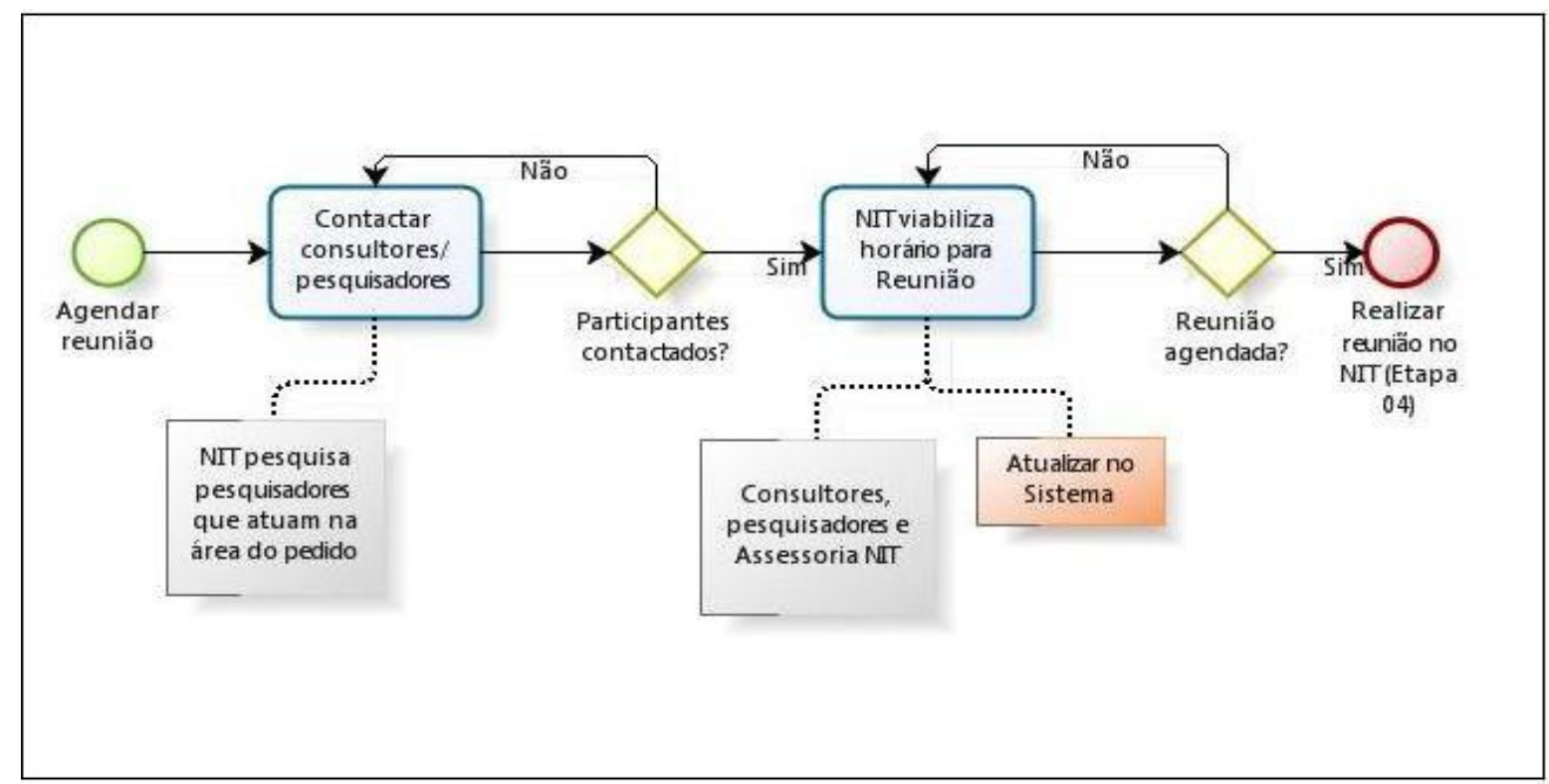

Figura 6 Etapa 3 Agendamento de reunião de AVTE Fonte: próprio autor 


\section{Etapa 4 Reunião de Análise de Viabilidade Técnica e Econômica (AVTE):}

Analisa-se a anterioridade ou estado da técnica da invenção, faz-se o estudo da viabilidade técnica e econômica da invenção, realizada pelas Assessorias do NIT, as quais elaboram o parecer técnico da invenção, se reprovado vai para a Etapa 7 de licenciamento da invenção sem proteção de propriedade intelectual, se positivo pode-se encaminhar para Etapa 5 de redação de patente (Figura 7). Atualmente, não vem sendo feito a estudo de viabilidade econômica por falta de recursos humanos, sendo executada somente a análise técnica e um estimativa se há mercado para a tecnologia ou não.

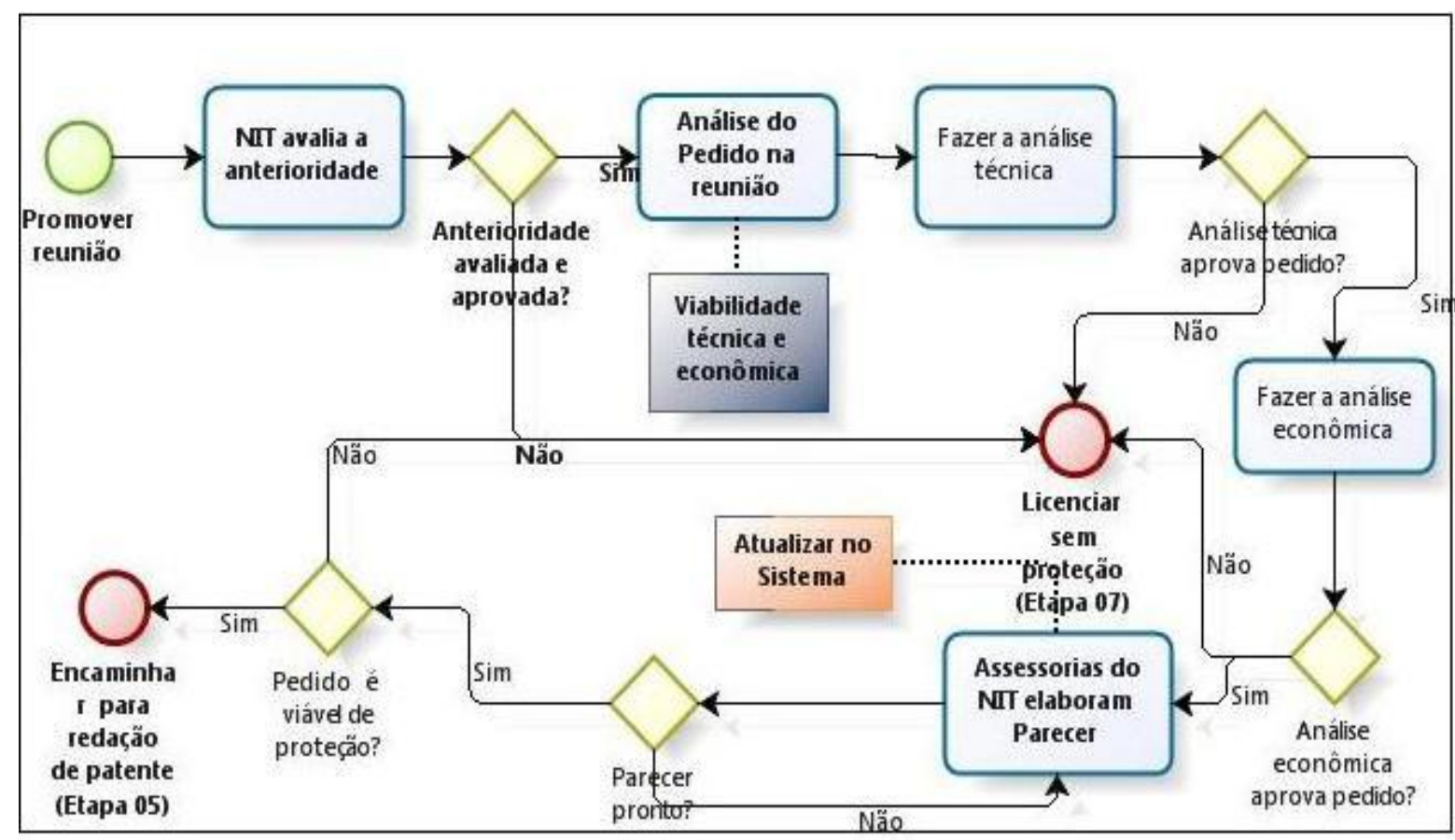

Figura 7 Etapa 4 Reunião de AVTE

Fonte: próprio autor

\section{Etapa 5 Redação e revisão de pedido de invenção}

Pesquisador (es) preenche $(\mathrm{m})$ formulários de cadastro da invenção a encaminha para escritório especializado fazer a redação conforme formato padrão exigido pelo INPI, após escritório repassar para o NIT, volta para pesquisador fazer revisão, se encontrar alguma correção, é remetida para escritório ajustar e assim gerar versão da minuta final de pedido de patente (Figura 8), a qual pode ser enviada para depósito junto ao INPI (Etapa 6). 


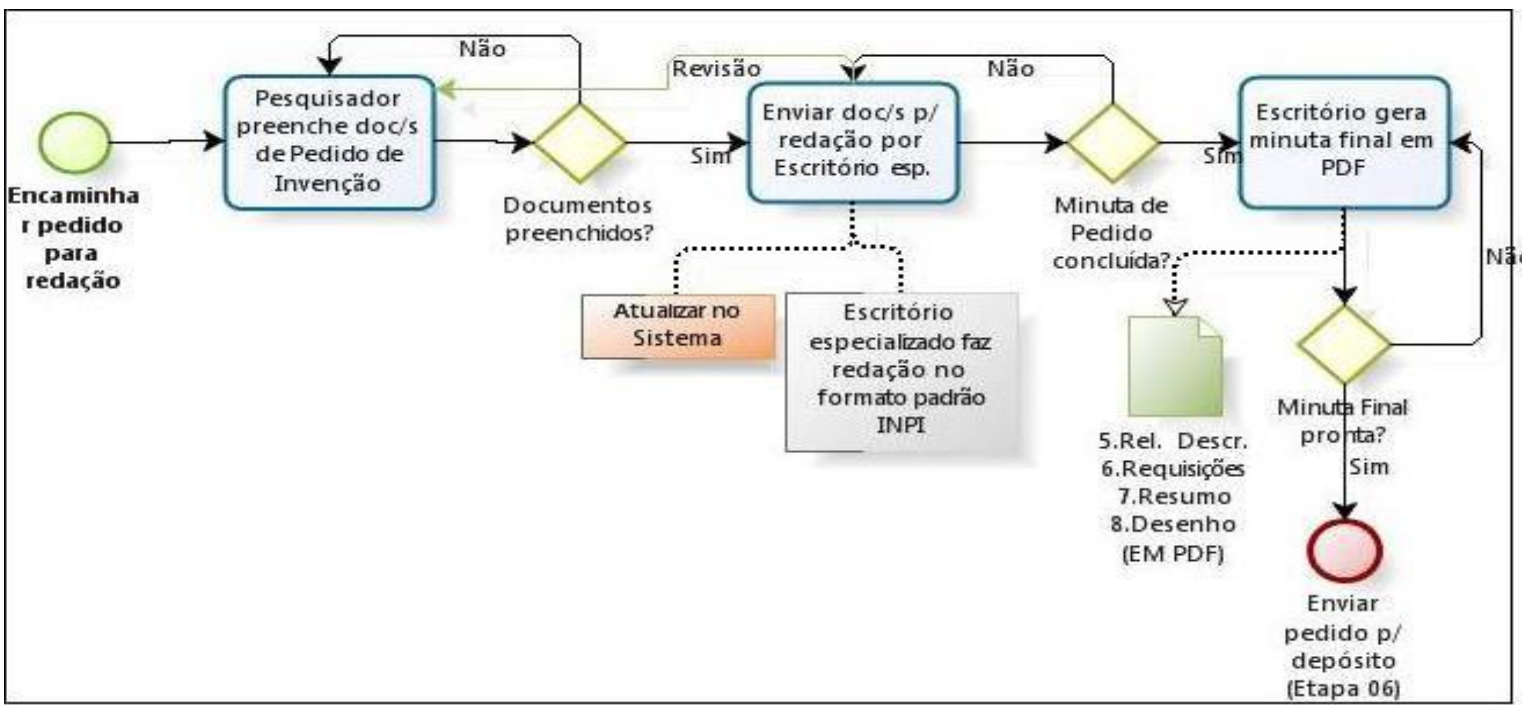

Figura 8 Etapa 5 Redação e revisão do pedido de invenção

Fonte: próprio autor

\section{Etapa 6 Depósito de pedido de invenção}

NIT recebe minuta final do pedido e prepara os demais documentos para envio para depósito no INPI. Dentre esses documentos precisam constar: petição de depósito do pedido, relatório descritivo (minuta final), termo de posse do reitor (cópia), diário oficial da posse, CPF (cópia), RG (cópia) e guia de recolhimento a União - GRU (taxa do depósito) e outra guia de recolhimento para a Instituição (Contabilidade). Tendo isso, funcionário do NIT encaminha pessoalmente a documentação para o INPI (Figura 9).

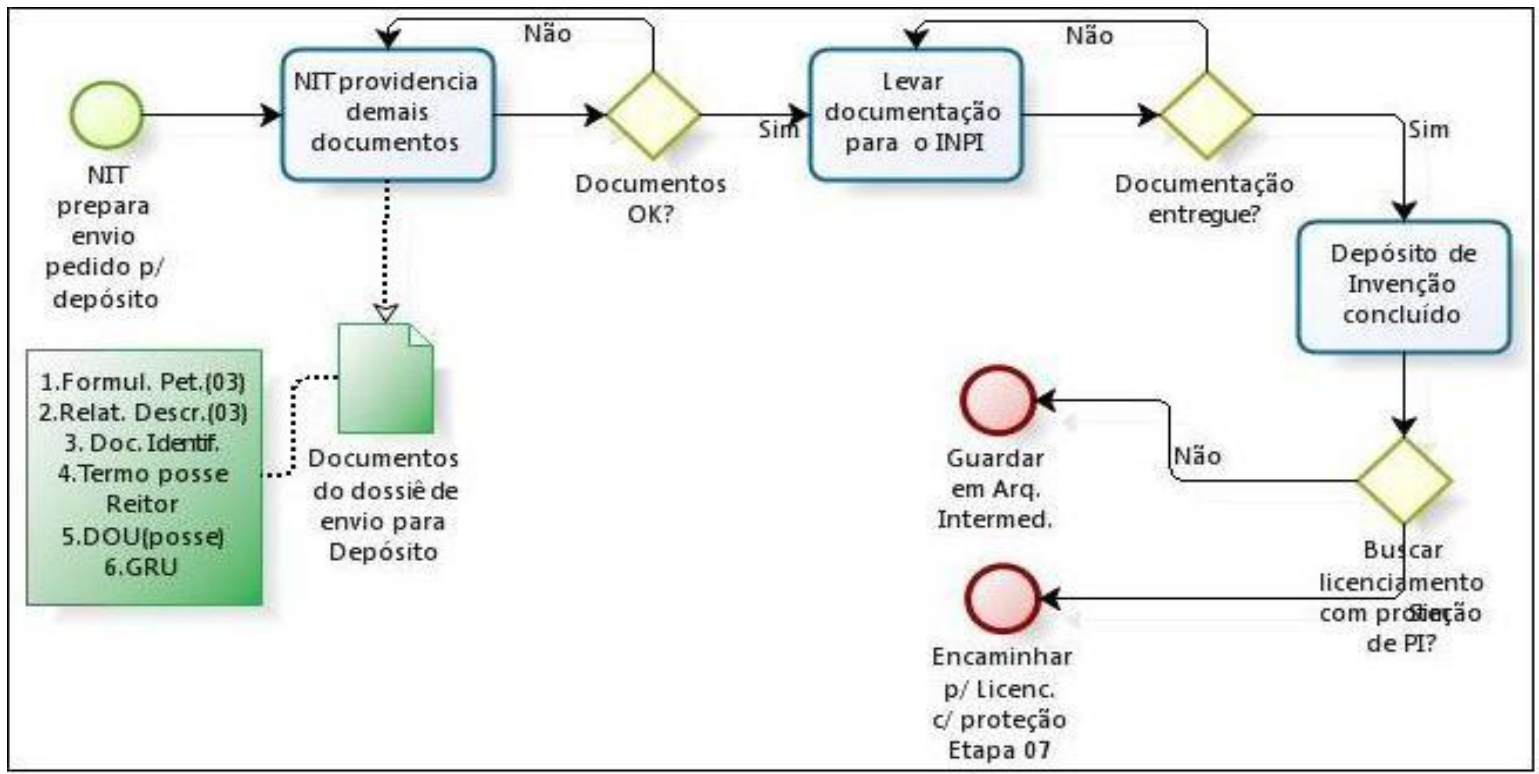

Figura 9 Etapa 6 Depósito de patente

Fonte: próprio autor

\section{Etapa 7 Licenciamento de invenção}

O NIT analisa e constata que invenção pode ser encaminhada para licenciamento com uma empresa e/ou Indústria, sendo assim, deve pesquisar potenciais empresas que possam promover industrialização de invento com ou 
sem proteção de propriedade intelectual. Assim, NIT entre em contato e convida representantes para participar da reunião, fornecendo apoio na elaboração de contrato de licenciamento, convênio ou cooperação técnico científico, verificando a partir disso, o devido cumprimento de tal documento (Figura 10).

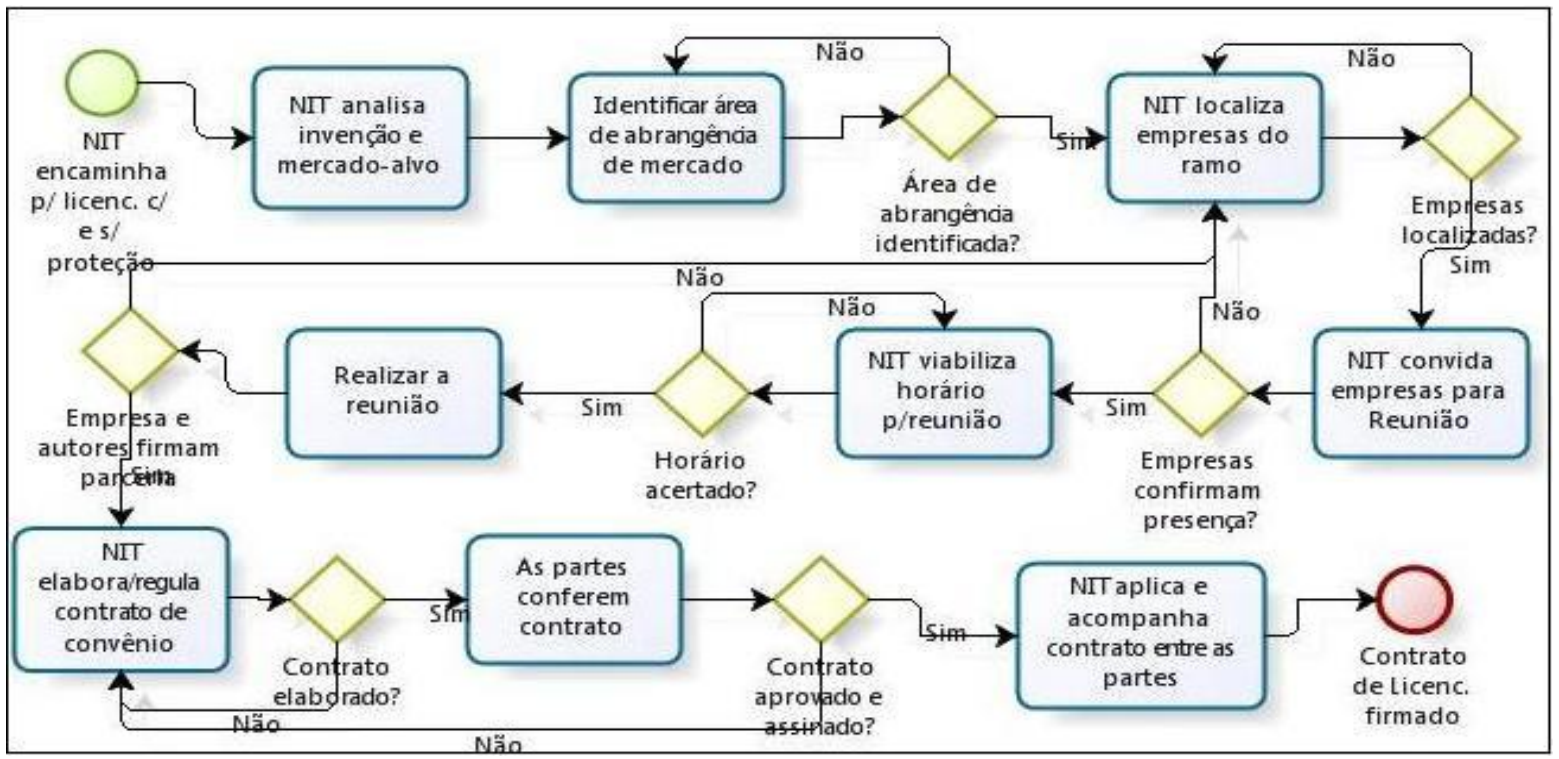

Figura 10 Etapa 7 Licenciamento da tecnologia

Fonte: próprio autor

Dessa forma, tendo-se definido o fluxo de processos do NIT, obtêm-se a clareza para o aumento de desempenho das atividades-fim do núcleo, especificamente do encaminhamento de pedidos de patente, reproduzindo a eficiência e a eficácia junto a sua gestão de produção.

Essa pesquisa atuou com foco específico na tramitação de processos do NIT, e almejou colaborar com o desenvolvimento de um modelo para sistema mais próximo da realidade do usuário, para o acompanhamento e recuperação de informações relativas à proteção da propriedade intelectual gerada no decorrer das atividades-fim da Universidade (ensino, pesquisa e extensão). Da mesma forma, também obteve-se como resultado a maior difusão das produções científicas e tecnológicas da academia, considerando o conhecimento sobre existência de uma rede de comunicação bem estabelecida entre os escritórios de propriedade intelectual pelo mundo, citando dentre esses: INPI (Brasil), USPTO ${ }^{8}$ (USA), Espacenet ${ }^{9}$ (Europa), JPO ${ }^{10}$ (Japão) e outros.

$O$ ideal dessa pesquisa se transparece em promover melhorias para 0 sistema utilizado atualmente pela Instituição (SIE), trazendo-o mais próximo da realidade do usuário do NIT. Trata-se da sistematização das tarefas necessárias para o fluxo de processos de encaminhamento para proteção de propriedade intelectual, conforme determinado e exigido em legislação decorrente.

\footnotetext{
8 Endereço eletrônico: <http://www.uspto.gov/>; acesso em 07 Dez 09.

9 Endereço eletrônico: <http://ep.espacenet.com/ >; acesso em 07 Dez 09.

10 Endereço eletrônico: <http://www.jpo.go.jp/>; acesso em 07 Dez 09.
} 
A seguir pode-se visualizar uma tela do módulo de protocolo e controle de processos - MPCP/SIE (Figura 11), o qual será utilizado algumas das suas funções para o planejamento da criação do Módulo de Propriedade Intelectual. Na figura pode se visto a tela de abertura de processos (administrativo, acadêmico, entre outros), a qual será adotada as funcionalidades que possam fornecer informações necessárias sobre o acompanhamento e recuperação dos dados dos processos.

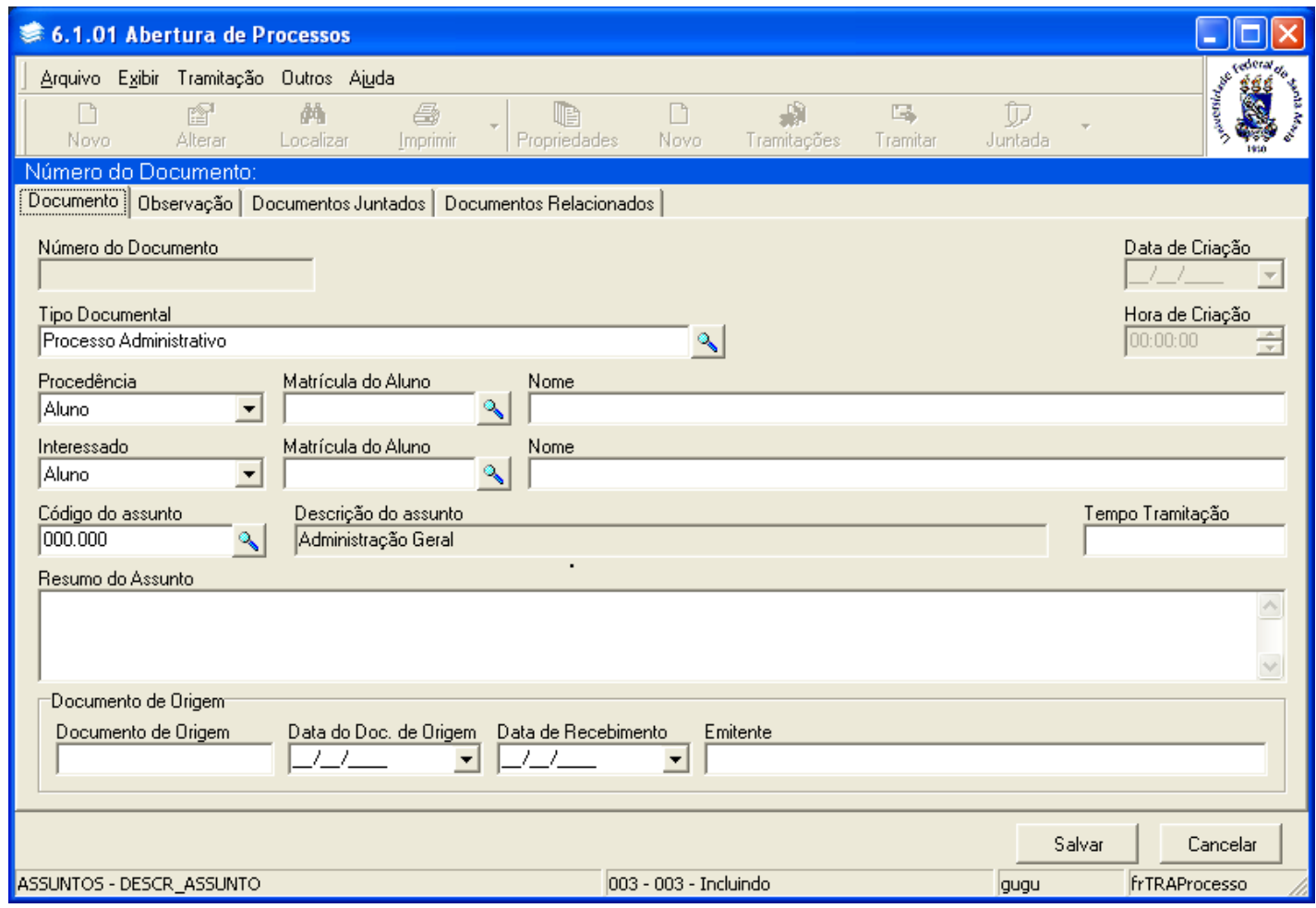

Figura 11 Tela do módulo de abertura de processo do SIE

Esse sistema é adotado atualmente pela Instituição e, com base em depoimentos dos usuários, observam-se inúmeras necessidades a serem incorporadas aos seus módulos, as quais poderiam promover uma maior interação com a realidade vivenciada do usuário.

Essa maneira de obtenção de requisitos pode inspirar a criatividade do analista que, por sua vez, pode desenvolver um produto mais adequado ao ambiente, sempre atento para os vícios e limitações dos atores envolvidos.

A comunicação entre o desenvolvedor e o utilizador é fundamental para a eficiente sistematização de atribuições e tarefas. Essas ações podem romper com crenças e paradigmas, realidade promovida pela forte visão interdisciplinar exigida pelo mercado, o qual se encontra em constantes desafios e obstáculos, enfrentando mudanças em alta rotatividade como oportunidades de melhorias e maior desenvolvimento para um empreendedor.

O Arquivista está inserido no fazer da gestão informacional de qualquer organização, em se tratando da sua natureza do fazer interdisciplinar e multidisciplinar, envolvido em um ambiente que vislumbra forte inserção de tecnologias de gerenciamento da informação, desde o controle administrativo até o elaboração e venda de produtos ou prestação de serviços. 


\section{$5 \quad$ CONCLUSÕES}

Esse trabalho fornece embasamento para a elaboração de um modelo para sistema de gestão de propriedade intelectual em Instituições de Ensino Superior (IES), com foco nos processos de encaminhamento para proteção das invenções geradas das produções científicas desenvolvidas na UFSM. Essa pesquisa mostra resultados pertinentes em fluxogramas a serem propositados à implementação de desenvolvimento do SGPI.

Os resultados dessa pesquisa podem também contribuir para 0 cumprimento das metas do projeto interinstitucional de implementação de núcleos de inovação tecnológica em universidades gaúchas, mais especificamente com o desenvolvimento de metodologia para sistema de gerenciamento da propriedade intelectual, o qual cumpra os requisitos necessários para a melhoria do desempenho nos NIT's, denominação adotada para os setores que gerenciam o encaminhamento para proteção da propriedade intelectual da sua instituição.

Nessa proposta, foi fundamental o uso da técnica de análise contextual de tarefa, o qual contribuiu eficientemente na obtenção dos requisitos dentro dos parâmetros esperados pelos usuários, considerando que o próprio pesquisador vivenciou a atividade de usuário do sistema durante todo o decorrer da pesquisa.

Essa técnica apresentada não é nova, mas o seu uso para o desenvolvimento de sistemas de informação deve ser explorado dentro de um contexto mais amplo, que privilegie o diálogo necessário entre usuários e desenvolvedores. Ao estabelecer parâmetros de construção mais próximos ao mundo habitual dos reais utilizadores da aplicação e ao desenvolver uma forma de observação centrada na resolução dos problemas (tarefas) do usuário, a técnica explanada durante o artigo pode auxiliar nas primeiras etapas do desenvolvimento de um sistema de informação, principalmente no que concerne à reorganização das tarefas que, por muitas vezes, é necessária para uma posterior implementação de sistemas automatizados.

Em relação aos fluxos documentais, percebe-se a necessidade de uma sinergia completa entre todos os participantes do processo, para que os profissionais ligados à Ciência da Informação não se restrinjam a sua área de atuação, tornando-se apenas fiéis depositários das informações. A presença de profissionais da ciência da informação é imprescindível na definição dos processos e não, apenas, na fiscalização da execução dos mesmos. Desta forma, técnicas como a Análise Contextual de Tarefas mostram-se como importantes ferramentas para que os diferentes profissionais possam se comunicar utilizandose de uma linguagem comum que possa ser compreendida por todos e que permita suficiente expressividade para que os diferentes olhares (arquivísticos, administrativos e tecnológicos) possam ser discutidos e implementados de forma satisfatória.

Esse modelo aproveita o potencial criativo do próprio usuário e sua experiência no convívio constante com a atividade específica a ser melhorada com a inserção do sistema. Dentro dos fluxos, fica visível a identificação dos documentos obtidos no cumprimento das funções cadastrais e conteudistas das tramitações. 
O fluxo de trabalho bem definido pode colaborar para um melhor controle da produção de documentos, onde se simplifica as funções e os métodos de trabalho para uma gestão documental mais eficiente e enxuta. Sabe-se que, os documentos pertinentes a operações repetitivas são, de modo geral, passíveis de padronização, tanto no estilo quanto no conteúdo (SCHELLENBERG, 2006).

A construção de sistemas bem uniformes e adequados à realidade do usuário, identifica a técnica de análise de tarefas, abordada nessa pesquisa, como uma metodologia recomendável para o desenvolvimento de sistemas de GED e Workflow, considerando toda a obtenção de dados que mostram as funcionalidades do ambiente, demonstrando suas maiores necessidades $e$ melhorias.

A análise contextual de tarefas é uma técnica que pode ser utilizada pelos arquivistas tendo em vista o exercício das suas atividades estarem vinculados diretamente com fluxo documental e no desenvolvimento da gestão de documentos que visam estabelecer padrões a serem seguidos pela organização em suas atividades.

Da mesma forma, essa técnica pode ser utilizada pelos desenvolvedores considerando a clareza obtida sobre as atividades realizadas pela organização, promovendo a criação de um sistema mais adequado conforme as necessidades da organização.

Os usuários do sistema conseguem visivelmente, obter um melhor desempenho de suas atividades quando da maior facilidade de absorção da nova tecnologia desenvolvida para seu ambiente diário, quando esse considerar o fator desse sistema ter sido desenvolvido sob os aspectos de sua própria atividade de trabalho.

Desta forma, o desenvolvimento do SGPI se insere na gestão dos processos de informação, incluindo assim todos os subprocessos que dele se derivam, envolvendo profissionais da arquivologia, administração e ciência da computação, pois é necessário o empenho destes três profissionais para a correta definição do sistema, considerando o fluxo documental gerado, o fluxo processual proposto e a implementação do modelo gerado.

É importante notar que a arquivologia e a administração, nesta proposta, se complementam pois assim como os profissionais da arquivística devem gerir o fluxo documental gerado pelo processo modelado, o processo, em si, em grande parte é o próprio fluxo documental e, desta forma, também recebe influência dos agentes ativos do processo (administradores, professores e pesquisadores em geral), que dele se utilizam para levar a cabo suas realizações.

\section{REFERÊNCIAS}

CALDERON, W. R. et al. O processo de gestão documental e da informação arquivística no ambiente universitário. Ciência da Informação, Brasília, v. 33, n. 3, p. 97-104, set./dez. 2004.

CANONGIA, C. et al. Foresight, inteligência competitiva e gestão do conhecimento: instrumentos para a gestão da inovação. Gestão \& Produção, São 
Carlos, v. 11, n. 2, p. 231-238. maio./ ago. 2004. Disponível em: <http://www. scielo.br/pdf/gp/v11n2/a09v11n2.pdf> Acesso em: 16 nov. 2009.

CORDENONSI, A. Z.; BERNARDI, G.; COSTA, E. S. A análise contextual de tarefas no desenvolvimento de fluxo de informações. In: SIMPÓSIO BRASILEIRO DE SISTEMAS DE INFORMAÇÃO, 4., 2008. Rio de Janeiro. Anais... Rio de Janeiro: UNIRIO, 2008. p. 1-10.

ETZKOWITZ, H. Hélice Tríplice: universidade-indústria-governo: inovação em movimento. Porto Alegre: EDIPUCRS, 2009.

FIGUEIREDO, P. N. Gestão da inovação: conceitos, métricas e experiências de empresa no Brasil. Rio de Janeiro: LTC. 2009. 340p.

HOELZEL, C. G. M. Design ergonômico de interfaces gráficas humano computador: um modelo de processo. 2004. 176p. Tese (Doutorado em Engenharia da Produção)- Universidade Federal de Santa Catarina, Florianópolis, 2004.

OLIVEIRA, A. F. N. et al. O processo de gestão documental e da informação nas bibliotecas universitárias públicas e privadas. In: ENCONTRO NACIONAL DE ESTUDANTES DE BIBLIOTECONOMIA, DOCUMENTAÇÃO, GESTÃO E CIÊNCIA DA INFORMAÇÃO, 33., 2010. Paraíba. Anais... Unniversidade Federal da Paraíba: UFPB. 2010. 12p.

PREECE, J.; ROGERS, Y; SHARP, H. Design de interação: além da interação homem-computador. Trad. Viviane Possamai. Porto Alegre: Bookman, 2005. $548 p$.

SANTOS, V. B.; INNARELLI, H. C.; SOUZA, R. T. B. Arquivística: temas contemporâneos: classificação, preservação digital, gestão do conhecimento. Distrito Federal: SENAC, 2009. 224p.

SCHELLENBERG, T. R. Arquivos modernos: princípios e técnicas. Tradução de Nilza Teixeira Soares. 6. ed. Rio de Janeiro: FGV. 2006. 388p.

SCHERER, F. O.; CARLOMAGNO, M. S. Gestão da inovação na prática: como aplicar conceitos e ferramentas para alavancar a inovação. São Paulo: Atlas. 2009. 150p.

TONSIG, S. L. Engenharia de software: análise e projeto de sistemas. São Paulo: Futura, 2003. 351p.

VITAL, L. P.; FLORIANI, V. M.; VARVAKIS, G. Gerenciamento do fluxo de informação como suporte ao processo de tomada de decisão. Informação \& Informação, Londrina. v. 15, n. 1 , p. 85-103, jan.jjun. 2010. Disponível em: <http://www.uel.br/revistas/uel/index.php/informacao/article/viewFile/5335/5880> Acesso em: 16 nov. 2009. 


\title{
Title
}

The use of Contextual Task Analysis for the management of intellectual property

\begin{abstract}
This paper presents the development of a model for intellectual property management through the use of the contextual tasks analysis methodology and based on the users' perspective. It presents a case study where the suggested approach is applied to identify the model requirements. It develops a model which demonstrates the improvements in process management and intellectual property protection, and provides evidences stating the importance of applying management tools to enhance intellectual protection in organizations. Positive findings were verified as a result of data and work flow management, which proved to improve efficiency in data recovery and, consequently, the innovative performance of the organization.
\end{abstract}

\section{Keywords}

Innovation. Requirements Analysis. Task Analysis. Intellectual Property. Innovation Management

\section{Titulo}

El uso de Análisis Contextual de Tarea para la gestión de la propiedad intelectual

\section{Resumen}

En este trabajo se presenta el desarrollo de un modelo para sistema de gestión de la propiedad intelectual a través de la utilización de la metodología de análisis contextual de tareas, que visa desarrollar un modelaje bajo la perspectiva de los usuarios. Se presenta un estudio de caso donde se aplica el enfoque propuesto para identificar los requisitos del modelo. Tiene como objetivo desarrollar un modelo que demuestra las mejorías en la gestión de procesos de protección de la propiedad intelectual, y que proporcione datos que muestren la importancia del uso de herramientas de gestión como medio de mejorar la protección intelectual en las organizaciones. Los resultados obtenidos por medio del desarrollo de flujo y con la estruración de las atividades, fueron positivos, mejorando la eficiencia en la recuperación de datos y, en consecuencia, el aumento de la capacidad de innovar de la organización.

Palabras clave: Innovación. Análisis de Requerimientos. Análisis de tareas. Propiedad Intelectual. Gestión de Innovación.

Recebido em: 01/11/2010

Aceito em: 11/02/2011 